\title{
Using the Support Immersion Endoscope for Socket Assessment
}

\author{
Gintaras Juodzbalys, * Stasys Bojarskas, * Ricardas Kubilius, * and Hom-Lay Wang ${ }^{\dagger}$
}

Background: The purpose of this study was to determine the indications, efficacy, and advantages of the support immersion endoscope (SIE) method for extraction socket assessment.

Methods: Twelve patients (four women and eight men; mean age: 28 years) in need of extraction with implant placement participated in the study. The teeth extracted included eight upper central incisors and six upper lateral incisors. Extraction sockets were evaluated with a conventional extraction site evaluation (CESE) method alone or with CESE + SIE. CESE includes: visual evaluation; periodontal probing; ridge mapping with calipers, dental mirror, and orthopantomogram; and diagnostic wax-up.

Results: CESE + SIE had significantly better accuracy in examining extraction socket labial plate vertical position, labial plate thickness, and bone quality compared to CESE alone. The results obtained from CESE assessment were inconsistent because of poor visualization.

Conclusion: The SIE can be used as an adjunct tool in assessing extraction socket morphology and bone conditions without flap elevation. J Periodontol 2008;79:64-71.

\section{KEY WORDS}

Dental implants; endoscope; esthetics.

\footnotetext{
* Department of Oral and Maxillofacial Surgery, Kaunas University of Medicine, Kaunas, Lithuania.

$\dagger$ Department of Periodontics and Oral Medicine, University of Michigan, Ann Arbor, MI.
}

I mmediate surgical placement of implants following tooth extraction reduces the overall treatment time and allows for better prosthetic rehabilitation because it guides the clinician toward proper implant placement. ${ }^{1-4}$ As documented in the literature, ${ }^{5,6}$ an average of 2 to $2.5 \mathrm{~mm}$ of horizontal bone resorption and $1 \mathrm{~mm}$ of vertical bone resorption occur following tooth extraction. This type of bone resorption often takes place within the first 3 to 6 months after the tooth is removed. ${ }^{6}$ It also has been shown that this type of resorption is pronounced up to $50 \%$ on the buccal side because of a higher content of bundle bone. Hence, it creates a challenge for the clinician to place the dental implant in the ideal position. Many researchers ${ }^{1-4}$ believed that this could be minimized by placing an implant at the time of tooth extraction. Unfortunately, as demonstrated by Araujo et al. ${ }^{7-10}$ in their series of experiments, the surgical placement of an implant in the fresh extraction site failed to prevent the remodeling that occurred in the walls of the socket. Therefore, it has been suggested that when planning implant placement in fresh extraction sockets, clinicians must take into consideration the future bone resorption that may occur. ${ }^{11}$

Recently, the definition of implant success has been revised to include an optimal esthetic result as well as osseointegration. ${ }^{12}$ The level of bone support and the soft tissue dimensions surrounding the implant-supported restoration are two of the most important factors that

doi: 10.1902/jop.2008.070253 
influence the esthetic outcome. ${ }^{13}$ Labial plate position, thickness, and bone loss are important considerations for esthetic implantation and, in many cases, they may necessitate hard tissue augmentation. ${ }^{14,15}$

Furthermore, the success of immediate implant procedures may be jeopardized by the presence of periodontal infection ${ }^{16,17}$ due to difficulties in flap manipulation and the ability to eradicate infection from the hard tissues. ${ }^{17,18}$ Also, to ensure successful osseointegration during immediate implantation, bone augmentation often is indicated in areas of insufficient bone support. ${ }^{18-23}$

Hence, to ensure proper implant function as well as esthetics, it is essential to examine the extraction socket and surrounding structures carefully, especially with immediate implantation following tooth extraction. ${ }^{24}$ Although there are many ways to assess the socket, raising the flap is the most commonly recommended technique. However, flap elevation often results in poor blood supply, more bone loss, delayed wound healing, and compromised soft tissue appearance. Nonetheless, to evaluate an extraction socket properly without flap elevation can be difficult because of poor visualization. The support immersion endoscope (SIE) is a tool that can overcome this challenge. In clinical dentistry, endoscopes are used for endodontic applications, ${ }^{25}$ the evaluation of conventional sinus floor augmentation, ${ }^{26}$ and subantroscopic laterobasal sinus floor augmentation. ${ }^{27} \mathrm{SIE}$ can be a complementary method to radiographs of implant sockets. ${ }^{28,29}$

Nevertheless, endoscopy has not been used for the assessment of implant cavities because endoscopic visualization was hindered because of the rapid staining of the optic device caused by bleeding in the cavity. In 2002, Engelke ${ }^{28}$ proposed the use of the SIE method, which is based principally on endoscope application with support and possible continuous irrigation. This permits an interface-free observation of bone structures in a liquid medium. SIE allows magnification and digital recording of the field.

The aim of this study was to determine the indications and to identify the efficacy and advantages of the SIE method for extraction socket evaluation, specifically in the anterior maxillary region.

\section{MATERIALS AND METHODS}

\section{Subjects}

The subjects for the present study were consecutively recruited patients referred to the Department of Maxillofacial Surgery, University of Kaunas, for single-tooth extractions, implant therapy, and implant-supported restorations in the maxillary incisor tooth region. For inclusion, the patients did not have traumatic or inflammatory soft and hard tissue destruction at the extraction site nor did they require restorative treatment of the adjacent teeth, and they were in good general health as evaluated by a completed general health questionnaire and clinical judgment. All patients underwent a pretreatment examination that included radiographs, impressions, stone casts, and a diagnostic wax-up.

All study participants read and signed an informed consent form. The use of human subjects in this study was reviewed and approved by the Health Science Institutional Review Board of the University of Kaunas. This study was conducted from April 1, 2004 to December 1, 2006. Twelve subjects (four women and eight men; mean age: $28 \pm 9.1$ years) were included in the study.

\section{Tooth Extraction}

After administering local anesthesia, ${ }^{\dagger}$ teeth were extracted gently, and extreme care was taken to avoid fracture of the socket walls. To achieve this aim, an intrasulcular incision, using a $15 \mathrm{c}$ blade, was made around the maxillary tooth to be extracted and the proximal palatal aspect of the adjacent teeth. A minimal palatal flap, with releasing incisions, also was reflected. A palatal approach was used for atraumatic tooth extraction, followed by careful removal of granulation tissue, epithelium, and bone inserting Sharpey's fibers from the socket wall lining.

\section{Extraction Socket Assessments}

Assessments of the extraction socket were performed immediately after tooth extraction by one examiner (GJ) trained to obtain accurate and reproducible measurements and indices. ${ }^{30}$

\section{Conventional Extraction Socket Evaluation (CESE)}

The CESE included the following soft and hard tissues assessments. Soft tissue contour variations: possible distance between socket wall and adjacent teeth gingival scallop. No soft tissue contour variations and $<2$ $\mathrm{mm}$ were defined as adequate and compromised, respectively. ${ }^{15}$ The keratinized gingival width was measured on the buccal side of the treatment area. Vertical soft tissue deficiency: the distance between socket wall and adjacent teeth buccal mucosa tissues. Gingival tissue biotype was characterized by fibrotic gingival thickness as thick $(\geq 1.5 \mathrm{~mm})$ or thin $(<1.5 \mathrm{~mm}))^{31}$ The mesio-distal distance between adjacent teeth: the distance measured in a mesio-distal direction between the two adjacent cemento-enamel junctions (CEJs). Duplicate measurements were made for each of the aforementioned parameters, and the mean value was calculated.

Soft tissue quality: evaluation was based upon the information collected from soft tissue color, consistency, and contour variations and was determined

‡ Ubistesini, 3M ESPE Dental, Seefeld, Germany. 
as good (pink, firm, and normal contour appearance) or fair (slightly red color, soft spongy, and uneven soft tissue contour). Extraction socket labial plate vertical position: the distance between the tip of the extraction socket labial plate and the CEJ line of the adjacent teeth. Triple recordings were performed, and the mean value was calculated. Extraction socket facial bone thickness was estimated with ridge-mapping calipers. Measurements were done in a vertical plane in the labial plate at points from 1 to $6 \mathrm{~mm}$ from the labial plate tip. Triple recordings were performed, and the mean value was calculated. Extraction socket bone lesions (periodontal and traumatic bone lesions) were identified visually using a dental mirror and sounding with the tip of a periodontal probe. All linear measurements were performed to the closest $1 \mathrm{~mm}$ with a periodontal probe. $\S$

\section{Extraction Site Evaluation Using SIE}

SIE was performed as described by Engelke et al. ${ }^{29}$ In the present study, an endoscopel unit was used that consisted of either 4 or $2.7 \mathrm{~mm}$ diameter, $30^{\circ}$ direction of view telescopes, support and irrigation shaft with a continuous irrigation system, light source, digital image processor, and monitor. Additionally, a thin (2-mm diameter) suction shaft with suction equipment was incorporated. Saline solution was pumped continuously out of the alveolus using suction. The suction shaft also served as a retractor of the alveolar soft tissues. SIE with irrigation was used for the assessment of all intra-alveolar parameters. Inserting the telescope into the extraction socket allowed macroscopic examination of socket structures, including socket bone lesions. External observation SIE was used to examine the socket labial plate vertical position and socket facial bone thickness.

The deepest resorption site of the labial plate and vertical resorption level were assessed using SIE and a periodontal probe. The thickness of the extraction socket labial plate was measured in the same manner, using ridge-mapping calipers and the SIE. Triple recordings were performed, and the mean value was calculated.

The magnification used with the SIE depends on the cavity wall. At a distance of $5 \mathrm{~mm}$, the lens magnification factor is $\times 3$; at $2 \mathrm{~mm}$, it increases to $\times 10$. Together with the camera zoom of $\times 2$ to $\times 4$, magnification similar to a surgical microscope is achieved.

To ensure the proper comparison, an actual measurement of extraction socket parameters with flap access was performed in three cases in need of late implantation. The flap access measurement was performed after the CESE and SIE measurements. The results indicated that the SIE was more accurate (within $0.5 \mathrm{~mm}$ ) than the CESE method $(>1-\mathrm{mm}$ difference).

\section{Statistical Analysis}

Statistical analysis was performed using a software program. "I Means \pm SD were calculated. The paired $t$ test was applied for comparison of means and standard deviations. The Friedman two-way analysis of variance (ANOVA) was applied to show the differences in extraction socket assessments with one method. The Wilcoxon matched-pairs signed-rank test was applied to detect differences between assessments obtained using two methods of examination. A $P$ value $\leq 0.05$ was chosen as the threshold for statistical significance.

\section{RESULTS}

Fourteen teeth in the frontal maxilla were extracted: eight central incisors and six lateral incisors. Reasons for extraction included root fracture, perforation, periapical infection, and untreatable caries (Table 1).

Criteria for extraction site assessment was considered objective and subjective (Tables 2 through 4 ). Results obtained from this study indicated that CESE and CESE + SIE were useful in determining soft tissue health. Nonetheless, the addition of SIE allowed magnification and digital recording of an extraction site (Fig. 1). Furthermore, exposure and direct visual examination of the extraction site using the endoscope revealed different values of certain objective and subjective criteria compared to CESE.

The paired-samples $t$ test revealed a statistically significant difference between the data recorded with CESE and that recorded with CESE + SIE with regard to two assessments: extraction socket labial plate vertical position (Fig. 2) and labial plate thickness (Fig. 3; Table 2).

The extent of the vertical position of the extraction socket labial plate was $4.45 \pm 2.19 \mathrm{~mm}$ if CESE was applied and $3.64 \pm 2.0 \mathrm{~mm}(P<0.01)$ if CESE + SIE was used (Table 3). CESE + SIE (mean rank, 4.25) showed more accuracy than CESE (mean rank, 7.5) $(P<0.01)$. The power of the study was strong and reached 0.8 . The Friedman two-way ANOVA showed that the intraobserver accuracy of measurements was not significantly different if the same method of assessment was used.

The thickness of the extraction socket facial bone was $2.37 \pm 0.54 \mathrm{~mm}$ when CESE was used and $2.14 \pm 0.57 \mathrm{~mm}(P<0.001)$ when SIE also was applied. The distribution of the mentioned parameters at extraction sites is shown in Table 3. The Wilcoxon signed-rank test showed that CESE + SIE (mean rank, 3.0) was significantly more accurate than CESE (mean rank, 8.73) $(P<0.01)$. The power of the study

§ UNC-15 probe, Hu-Friedy, Chicago, IL.

\| Olympus endoscope and VISERA digital image processor and monitor,

Olympus, Tokyo, Japan.

II SPSS/PC+ version 13.0.1, SPSS, Chicago, IL. 
Table I.

\section{Subject and Defect Sites}

\begin{tabular}{|c|c|c|c|c|}
\hline Serial \# & Gender & Age (years) & Tooth \# & $\begin{array}{l}\text { Reason for Tooth } \\
\text { Extraction }\end{array}$ \\
\hline । & Male & 24 & 8 & Periapical infection \\
\hline 2 & Male & 30 & 8 & Root fracture \\
\hline 3 & Male & 18 & 9 & Root fracture \\
\hline 4 & Female & 42 & 7 & Periapical infection \\
\hline $5: 1$ & Male & 31 & 8 & Root fracture \\
\hline $5: 2$ & & & 9 & Periapical perforation \\
\hline 6 & Female & 49 & 8 & Root fracture \\
\hline $7: 1$ & Male & 28 & 8 & Root fracture \\
\hline $7: 2$ & & & 7 & Root fracture \\
\hline 8 & Male & 22 & 10 & Periapical infection \\
\hline 9 & Female & 26 & 9 & Periapical perforation \\
\hline 10 & Male & 19 & 10 & Root fracture \\
\hline 11 & Male & 24 & 7 & Caries \\
\hline 12 & Female & 27 & 9 & Caries \\
\hline Mean \pm SD & & $28.3 \pm 9.1$ & & \\
\hline
\end{tabular}

Serial \# = the number of the patients and quantity of the sockets examined. was 0.9. The Friedman two-way ANOVA showed that the intraobserver accuracy of measurements was not significantly different if the same method of assessment was used.

The subjective assessment of extraction site soft and hard tissue lesions (Figs. 4 and 5) showed that it was influenced significantly by the method of evaluation, either CESE or CESE + SIE (Table 4). Two (14.3\%) extraction sockets with bone lesions were identified only by using the CESE + SIE method.

Based upon the above data, SIE can be indicated for the following conditions: extent of vertical position of extraction socket labial plate, the thickness of extraction socket facial bone, and assessment of extraction site soft and hard tissue lesions.

\section{DISCUSSION}

Diagnosis and treatment planning are key factors for successful outcomes of immediate surgical placement of implants after tooth extraction. The efficacy of immediate implant placement is predictable if reasonable guidelines are followed. ${ }^{32}$ To achieve optimal esthetic implant rehabilitation, it is crucial to evaluate extraction socket bone volume and surrounding soft tissue status. ${ }^{13}$

Often, it is difficult to evaluate the conditions of extraction sockets properly without mucoperiosteal flap elevation. However, the surgical trauma inflicted by flap elevation may induce remodeling of the surface layer of the exposed alveolar bone. This results in bone resorption and, therefore, influences the thickness of the remaining bone facial to the implant following its placement. ${ }^{33}$ From a study of 2,685 implants, Spray et al. ${ }^{14}$ reported a mean facial bone loss of $0.7 \mathrm{~mm}$ between implant placement and abutment connection; the vertical bone loss increased significantly with decreased thickness of the bone at implant placement. Endoscopy can be a tool to overcome the need for flap elevation. This is a

$+=$ limited diagnostic possibilities; $++=$ accurate diagnosis available

* $P<0.01$.

$\dagger P<0.001$ 
Table 3.

\section{Assessments of Extraction Socket Labial Plate Vertical Position and Thickness (mm) Using CESE and CESE + SIE Methods}

\begin{tabular}{|c|c|c|c|c|c|c|c|c|c|c|c|c|c|}
\hline \multirow{3}{*}{$\frac{\text { Serial \# }}{1}$} & \multirow{3}{*}{$\frac{\text { Tooth \# }}{8}$} & \multicolumn{6}{|c|}{ Labial Plate Vertical Position } & \multicolumn{6}{|c|}{ Facial Bone Thickness } \\
\hline & & \multicolumn{3}{|c|}{ CESE } & \multicolumn{3}{|c|}{ CESE + SIE } & \multicolumn{3}{|c|}{ CESE } & \multicolumn{3}{|c|}{ CESE + SIE } \\
\hline & & 5 & 6 & 5 & 4 & 4 & 4 & 2.1 & 2.4 & 2.5 & 1.9 & 1.7 & 1.9 \\
\hline 2 & 8 & 2 & 3 & 3 & 2 & 2 & 2 & 3.0 & 2.9 & 3.2 & 3.0 & 3.0 & 2.8 \\
\hline 3 & 9 & 8 & 7 & 6 & 5 & 5 & 5 & 2.6 & 3.0 & 2.6 & 2.2 & 2.1 & 2.1 \\
\hline 4 & 7 & 6 & 3 & 5 & 4 & 4 & 4 & 3.1 & 3.0 & 3.3 & 2.8 & 2.8 & 2.8 \\
\hline $5: 1$ & 8 & 8 & 7 & 6 & 7 & 8 & 7 & 1.6 & 1.9 & 1.7 & 1.6 & 1.4 & 1.4 \\
\hline $5: 2$ & 9 & 5 & 4 & 5 & 3 & 3 & 3 & 2.6 & 2.2 & 2.4 & 1.8 & 1.9 & 1.8 \\
\hline 6 & 8 & 3 & 3 & 4 & 2 & 2 & 2 & 2.8 & 2.4 & 2.6 & 2.6 & 2.6 & 2.6 \\
\hline $7: 1$ & 8 & 0 & 0 & 0 & 0 & 0 & 0 & 3.3 & 3.0 & 3.2 & 3.1 & 3.1 & 3.1 \\
\hline $7: 2$ & 7 & 2 & 2 & 2 & 3 & 3 & 3 & 2.2 & 2.5 & 2.6 & 1.6 & 1.8 & 1.8 \\
\hline 8 & 10 & 8 & 8 & 9 & 8 & 7 & 8 & 1.3 & 1.4 & 1.2 & 1.1 & 1.3 & I.1 \\
\hline 9 & 9 & 5 & 6 & 6 & 4 & 4 & 4 & 2.0 & 1.8 & 2.1 & 2.0 & 2.0 & 2.0 \\
\hline 10 & 10 & 3 & 3 & 4 & 3 & 3 & 3 & 2.1 & 1.8 & 2.0 & 1.9 & 2.0 & 1.9 \\
\hline 11 & 7 & 4 & 5 & 5 & 3 & 3 & 3 & 2.1 & 2.4 & 2.3 & 2.1 & 2.1 & 2.1 \\
\hline 12 & 9 & 4 & 4 & 3 & 3 & 3 & 3 & 2.4 & 2.1 & 2.0 & 2.2 & 2.2 & 2.4 \\
\hline Mean rank & & & $7.5 *$ & & & 4.25 & & & $8.73 *$ & & & 3.0 & \\
\hline Mean \pm SD & & \multicolumn{3}{|c|}{$4.45 \pm 2.19 *$} & \multicolumn{3}{|c|}{$3.64 \pm 2.01$} & \multicolumn{3}{|c|}{$2.37 \pm 0.54 *$} & \multicolumn{3}{|c|}{$2.14 \pm 0.57$} \\
\hline
\end{tabular}

Serial \# = the number of the patients and quantity of the sockets examined.

* $P<0.001$ between CESE and CESE + SIE.

valuable diagnostic method in numerous medical disciplines, including dentistry. ${ }^{25-29}$ Our data indicated that clinical application of SIE during CESE did not result in any side effects that might have been caused by the pressure of irrigation or suction.

Results obtained with CESE showed that this method was adequate for assessing many objective (Table 2) and subjective (Table 4) soft and hard tissue parameters. However, SIE was better and more accurate for evaluating labial plate vertical position, facial bone thickness, and possible bone lesions.

Proper assessment of the vertical position of the extraction socket labial plate is important because surgical placement of an implant in the fresh extraction site fails to prevent the remodeling that occurs in the walls of the socket. ${ }^{7-10}$ The risk for soft tissue recession is proportional to the distance between the existing bone and soft tissue; the more distant the position of the alveolus to the soft tissues, the greater the risk for gingival recession. Adequate extraction socket labial plate vertical position is estimated to be $\leq 3 \mathrm{~mm} .{ }^{15}$ The extent of the vertical position of the extraction socket labial plate was $4.45 \mathrm{~mm}$ when CESE was used and $3.64 \mathrm{~mm}$ if SIE also was applied (Table 3). This indicated that SIE was helpful in recording the proper extraction socket labial plate vertical position. It is quite difficult to provide an objective examination of the extraction socket buccal plate vertical position using a periodontal probe, especially when significant vertical resorption is present. SIE improves the visualization of the extraction socket, which facilitates placement of the periodontal probe and the recording of accurate measurements.

Another important factor that is associated with immediate implant placement is the width of the extraction socket labial plate. A 1- to 2-mm distance is necessary to maintain the implant soft tissue profile and increase the likelihood of an esthetic outcome. ${ }^{14,15} \mathrm{~A}$ thin buccal alveolar plate often leads to partial or complete buccal plate loss following 
Table 4.

\section{Diagnostic Efficacy of CESE and CESE + SIE Methods for the Subjective Assessment of Extraction Site Soft and Hard Tissue Parameters}

\begin{tabular}{|c|c|c|c|c|c|}
\hline \multirow{2}{*}{$\begin{array}{l}\text { Criteria for Soft and Hard } \\
\text { Tissue Assessment }\end{array}$} & \multirow[b]{2}{*}{ Parameters } & \multicolumn{2}{|c|}{ Extraction Sites (N) } & \multicolumn{2}{|c|}{ Efficacy } \\
\hline & & CESE & CESE + SIE & CESE & CESE + SIE \\
\hline \multicolumn{6}{|l|}{ Soft tissue } \\
\hline \multirow[t]{2}{*}{ Soft tissue contour } & Adequate & 6 & 6 & \multirow[t]{2}{*}{++} & \multirow[t]{2}{*}{++} \\
\hline & Compromised & 8 & 8 & & \\
\hline \multirow{2}{*}{$\begin{array}{l}\text { Soft tissue quality (color, } \\
\text { consistency, and infection) }\end{array}$} & Good & 13 & 13 & \multirow[t]{2}{*}{++} & \multirow[t]{2}{*}{++} \\
\hline & Fair & 1 & । & & \\
\hline \multirow[t]{2}{*}{ Gingival tissue biotype } & Thick & 5 & 5 & \multirow[t]{2}{*}{++} & \multirow[t]{2}{*}{++} \\
\hline & Thin & 9 & 9 & & \\
\hline \multicolumn{6}{|l|}{ Hard tissue } \\
\hline \multirow[t]{2}{*}{ Extraction socket bone lesions } & No & 14 & 12 & \multirow[t]{2}{*}{+} & \multirow[t]{2}{*}{++} \\
\hline & Yes & 0 & 2 & & \\
\hline
\end{tabular}

$+=$ limited diagnostic possibilities; $++=$ accurate diagnosis available

healing. ${ }^{14}$ The thickness of the extraction socket facial bone was $2.37 \mathrm{~mm}$ when CESE was used and $2.14 \pm 0.57 \mathrm{~mm}$ when SIE was applied as well. The Wilcoxon signed-rank test showed that CESE + SIE (mean rank, 3.0) was significantly more accurate than CESE (mean rank, 8.73) $(P<0.01)$. Although the difference in the labial plate vertical thickness $(0.23 \mathrm{~mm})$ was statistically significant, its clinical importance remains to be determined.

The success of immediate implant procedures can be jeopardized by the presence of periodontal infection. ${ }^{16-18}$ With SIE, we were able to detect two (14.3\%) additional lesions that were not identified with the CESE method.

The improved accuracy of the SIE method for socket facial bone thickness assessment can be ex-

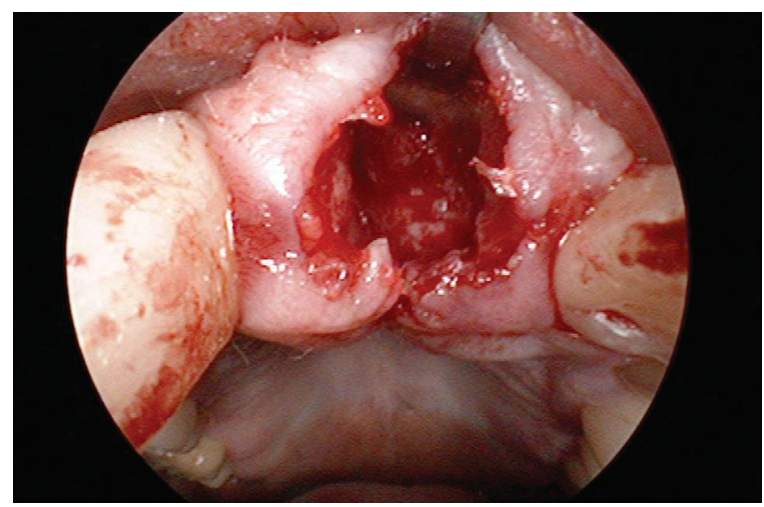

Figure $I$.

Panoramic view of extraction site assessed using an endoscope (lens magnification $\times 2$; camera zoom $\times 2$ ). plained by visual identification of the finest facial bone areas. It is difficult to guide the calipers properly when there is irregular facial bone resorption or fenestration defects. Furthermore, because of poor visualization, it is quite difficult to evaluate all facial bone area thicknesses using CESE.

From the three cases of actual measurement, we found that CESE + SIE was more accurate than the CESE method. This was possible because of improved visualization and ease of identification of the anatomical structures.

The limitations of using SIE in the clinic include its high price, space requirements, training time needed, and the time needed to assess the socket in addition to the time spent on CESE. Taking into account all of the benefits and limitations of the SIE method, we believe that this method is not appropriate for routine clinical usage, but rather it is indicated for a more challenging, difficult situation with a high esthetic demand. It also can be useful for the accurate quantification of the long-term effects of extraction socket facial bone thickness and labial plate vertical position on soft tissue preservation in research projects.

\section{CONCLUSIONS}

The SIE can be an adjunct tool to assist in the visualization of extraction socket morphology and bone

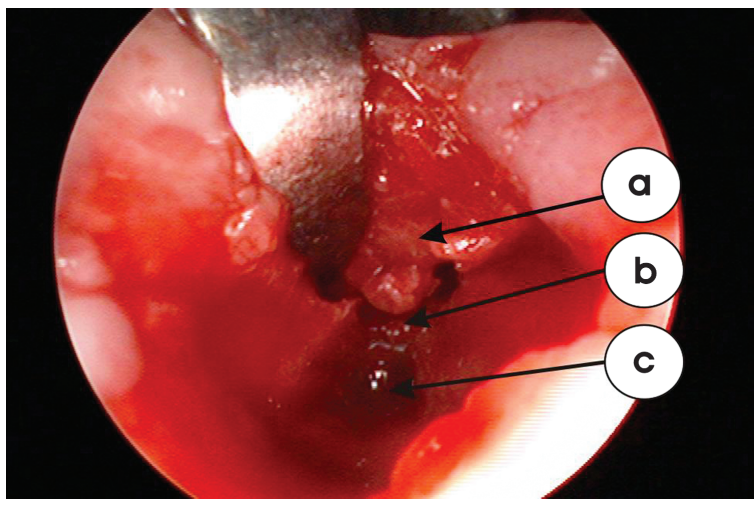

Figure 2.

Panoramic observation of the extraction socket. $a=$ buccal soft tissues; $b=$ labial plate vertical position; $c=$ apex of extraction socket. Labial plate resorption is evident. (Lens magnification $\times 4$; camera zoom $\times 2$.) 


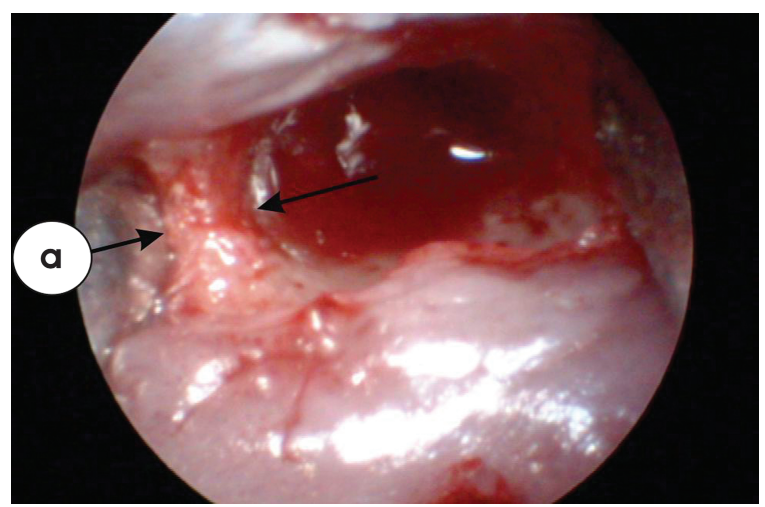

Figure 3.

Panoramic view of extraction site assessed using endoscope. $a=$ labial plate thickness. (Lens magnification $\times 4$; camera zoom $\times 2$.)

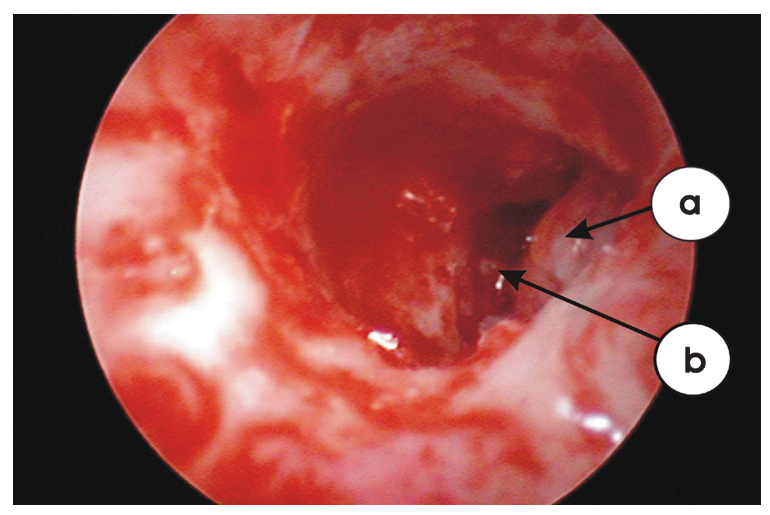

Figure 4.

Panoramic observation of the apical part of extraction socket. $a=$ granulations in apical region; $b=$ periodontal bone lesion. (Lens magnification $\times 10$; camera zoom $\times 2$.)

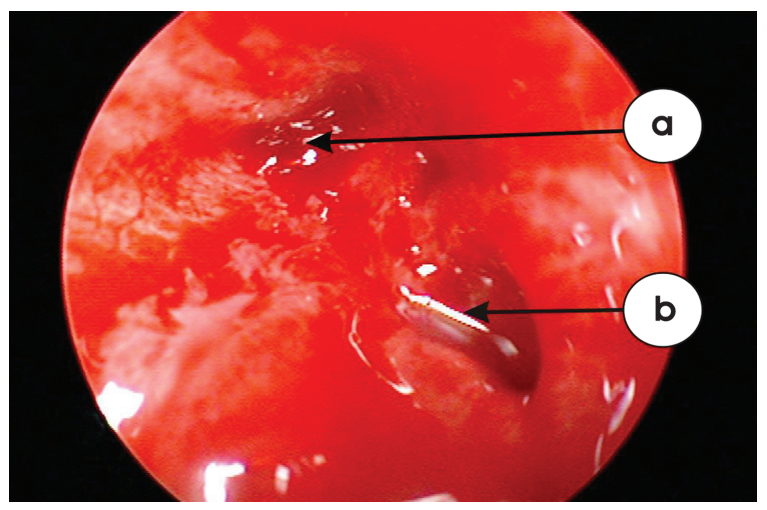

\section{Figure 5.}

Macroscopic observation of the extraction socket wall. $a=$ apex of extraction socket; $b=$ destruction of labial plate and fistula in soft tissues. (Lens magnification $\times 10$; camera zoom $\times 2$.) conditions. It is indicated commonly for the following extraction site assessments: vertical position of extraction socket labial plate, facial bone thickness, and extraction socket bone lesions.

\section{ACKNOWLEDGMENT}

The authors report no conflicts of interest related to this study.

\section{REFERENCES}

1. Denissen HW, Kalk W. Preventive implantations. Int Dent J 1991;41:17-24.

2. Werbitt MJ, Goldberg PV. The immediate implant: Bone preservation and bone regeneration. Int $J$ Periodontics Restorative Dent 1992;12:206-217.

3. Wheeler SL, Vogel RE, Casellini R. Tissue preservation and maintenance of optimum esthetics: A clinical report. Int J Oral Maxillofac Implants 2000;15:265-271.

4. Becker W, Hujoel P, Becker BE. Effect of barrier membranes and autologous bone grafts on ridge width preservation around implants. Clin Implant Dent Relat Res 2002;4:143-149.

5. Schropp L, Wenzel A, Kostopoulos L, Karring T. Bone healing and soft tissue contour changes following singletooth extraction: A clinical and radiographic 12-month prospective study. Int $J$ Periodontics Restorative Dent 2003;23:313-323.

6. Botticelli D, Berglundh T, Lindhe J. Hard-tissue alterations following immediate implant placement in extraction sites. J Clin Periodontol 2004;31:820-828.

7. Araujo MG, Sukekava F, Wennstrom JL, Lindhe J. Ridge alterations following implant placement in fresh extraction sockets: An experimental study in the dog. $J$ Clin Periodontol 2005;32:645-652.

8. Araujo MG, Lindhe J. Dimensional ridge alterations following tooth extraction. An experimental study in the dog. J Clin Periodontol 2005;32:212-218.

9. Araujo MG, Wennstrom JL, Lindhe J. Modeling of the buccal and lingual bone walls of fresh extraction sites following implant installation. Clin Oral Implants Res 2006;17:606-614.

10. Araujo MG, Sukekava F, Wennstrom JL, Lindhe J. Tissue modeling following implant placement in fresh extraction sockets. Clin Oral Implants Res 2006;17: 615-624.

11. Covani U, Cornelini R, Barone A. Bucco-lingual bone remodeling around implants placed into immediate extraction sockets: A case series. J Periodontol 2003;74: 268-273.

12. Saadoun AP, Landsberg TC. Treatment classifications and sequencing for post extraction implant therapy: A review. Pract Periodontics Aesthet Dent 1997;9:933941.

13. Belser UC, Bernard JP, Buser D. Implant-supported restorations in the anterior region: Prosthetic considerations. Pract Periodontics Aesthet Dent 1996;8:875 883.

14. Spray JR, Black CG, Morris HF, Ochi S. Influence of bone thickness on facial marginal bone response: Stage 1 placement through stage 2 uncovering. Ann Periodontol 2000;5:119-128.

15. Kazor CE, Al-Shammari K, Sarment DP, Misch CE, Wang H-L. Implant plastic surgery: A review and rationale. J Oral Implantol 2004;30:240-254. 
16. Rosenquist B, Grenthe B. Immediate placement of implants into extraction sockets: Implant survival. Int J Oral Maxillofac Implants 1996;11:205-209.

17. Grunder U, Polizzi G, Goene R, et al. A 3-year prospective multicenter follow-up report on the immediate and delayed-immediate placement of implants. Int J Oral Maxillofac Implants 1999;14:210-216.

18. Nemcovsky CE, Artzi Z, Moses O, Gelernter I. Healing of marginal defects at implants placed in fresh extraction sockets or after 4-6 weeks of healing. A comparative study. Clin Oral Implants Res 2002;13: 410-419.

19. Lazzara RJ. Immediate implant placement into extraction sites: Surgical and restorative advantages. Int $J$ Periodontics Restorative Dent 1989;9(5):332-343.

20. Block MS, Kent JN. Factors associated with soft- and hard-tissue compromise of endosseous implants. J Oral Maxillofac Surg 1990;48:1153-1160.

21. Becker W, Becker BB. Promotion around e-PTFE Augmented implants placed in immediate extraction sockets. In: Buser D, Dahlin C, Schenk RK, eds. Guided Bone Regeneration in Implant Dentistry, 1st ed. Chicago: Quintessence Publishing; 1994:137-155.

22. van Steenberghe D, Callens A, Geers L, Jacobs R. The clinical use of deproteinized bovine bone mineral on bone regeneration in conjunction with immediate implant installation. Clin Oral Implants Res 2000;11: 210-216.

23. Hämmerle CHF, Lang NP. Single-stage surgery combining transmucosal implant placement with guided bone regeneration and bioresorbable materials. Clin Oral Implants Res 2001;12:9-18.

24. Caplanis N, Lozada JL, Kan JY. Extraction defect assessment, classification, and management. J Calif Dent Assoc 2005;33:853-863.

25. Held SA, Kao YH, Wells DW. Endoscope - An endodontic application. J Endod 1996;22:327-329.
26. Wiltfang J, Merten HA, Ludwig A, Engelke W, Artz T. Roentgenologic, endoscopic and ultrasound evaluation of the maxillary sinus after sinus lift with simultaneous endosseous implantation (in German). Mund Kiefer Gesichtschir 1999;3(Suppl. 1):61-64.

27. Engelke W, Schwarzwäller W, Behnsen A, Jacobs HG Subantroscopic laterobasal sinus floor augmentation (SALSA): An up-to-5-year clinical study. Int $J$ Oral Maxillofac Implants 2003;18:135-143.

28. Engelke W. In situ examination of implant sites with support immersion endoscopy. Int J Oral Maxillofac Implants 2002;17:703-706.

29. Engelke W, Decco OA, Rau MJ, Massoni MC, Schwarzwaller W. In vitro evaluation of horizontal implant micromovement in bone specimen with contact endoscopy. Implant Dent 2004;13:88-94.

30. Polson AM. The research team, calibration, and quality assurance in clinical trials in periodontics. Ann Periodontol 1997;2:75-82.

31. Claffey N, Shanley D. Relationship of gingival thickness and bleeding to loss of probing attachment in shallow sites following nonsurgical periodontal therapy. J Clin Periodontol 1986;13:654-657.

32. Becker W. Immediate implant placement: Diagnosis, treatment planning and treatment steps/or successful outcomes. J Calif Dent Assoc 2005;33:303-310.

33. Cardaropoli G, Lekholm U, Wennstrom JL. Tissue alterations at implant-supported single-tooth replacements: A 1-year prospective clinical study. Clin Oral Implants Res 2006;17:165-171.

Correspondence: Dr. Gintaras Juodzbalys, Vainiku 12, LT46383 Kaunas, Lithuania. Fax: 370-37-323153; e-mail: gintaras@stilusoptimus.lt.

Submitted May 3, 2007; accepted for publication June 11, 2007. 